\title{
Using context and prosody in irony understanding: Variability amongst individuals
}

Elora Rivière, Madelyne Klein, Maud Champagne-Lavau

Aix Marseille Univ, CNRS, LPL, Aix-en-Provence, France

Manuscript accepted for publication in Journal of Pragmatics

Rivière, E., Klein, M. \& Champagne-Lavau, M. (2018). Using context and prosody in understanding irony: Variability amongst individuals. Journal of Pragmatics, 138, 165-172.

Corresponding author: Maud Champagne-Lavau, Ph.D.

Aix-Marseille Université

LPL, CNRS UMR 7309

5 Av. Pasteur

B.P. 80975

13604 Aix-en-Provence, France

Phone: (33) 0413552707

email: maud.champagne-lavau@univ-amu.fr 


\begin{abstract}
The present study sought to investigate, in French, the relative influence of both contextual incongruity and prosodic cues on irony comprehension and to explore whether individual differences exist regarding the relative influence of these markers of irony. Ninety-five participants, all native French speakers, were included in the study. They listened to a context followed by a target utterance presented with either an ironic prosody or a neutral prosody and then, they had to decide whether this target utterance was ironic or not. The stimuli were manipulated according to their degree of context incongruity between contextual information and the target utterance. The main results revealed that all participants relied on contextual incongruity to decide whether the speaker's utterance was ironic or not, whereas only a subgroup also used prosody to this interpretation task, highlighting individual differences in the use of prosody to decode irony. This study also confirmed that context seems to be a more powerful cue than prosody in judging irony.
\end{abstract}

Keywords: irony, sarcasm, contextual incongruity, prosody, individual differences 


\section{Introduction}

Verbal irony is a common form of non-literal language which requires the listener to differentiate what the speaker says from what one wants to mean using the relevant contextual information (Grice, 1975; Searle, 1979). More specifically, verbal irony can be defined as a type of utterance in which what is stated is different from or, in some cases, contrary to what the speaker means (Gibbs, 1986). Sarcasm is a subtype of verbal irony characterized by the expression of a negative and critical attitude concerning a recognizable victim or group of victims (Lee and Katz, 1998). Different psycholinguistic studies have demonstrated that interpretation of an utterance as ironic can be the result of an incongruity between context and speaker utterance (Colston and O'Brien, 2000; Ivanko and Pexman, 2003) whereas other studies have revealed that such an interpretation may be influenced by the speaker's prosodic pattern and specifically the intonational cues (Bryant and Fox Tree, 2002). However, less is known about how contextual incongruity interacts with prosodic cues in the comprehension of irony. Most studies exploring the role of contextual information in understanding irony have used written materials excluding the prosodic dimension while research on the influence of prosodic cues on irony comprehension dealt with single sentences. Thus, the present research - in French - focused on the relative impact of prosodic cues and contextual incongruity in understanding irony.

Several theories have been put forth in order to account for irony comprehension as a result of contextual incongruity. In the Allusion Pretense Theory by Kumon-Nakamura et al. (1995), contextual incongruity refers to the allusion to a failed expectancy meaning a contrast between what is expected and reality. More precisely, the allusion to a failed expectancy is defined as "an allusion to some prediction, expectation, preference, or norms that have been violated" (Kumon-Nakamura et al. (1995: 5)). Utsumi (2000) explains that, for an utterance to be understood as ironic, it has to occur in an ironic environment which implies that the speaker has an expectation, that this expectation is failed and finally that the speaker experiences a negative attitude towards the incongruity between his/her expectation and reality. For example, in (1) (Utsumi, 2000, p.1779), the mother's sentence "This room is totally clean!' is ironic. It makes an allusion to the mother's failed expectancy to find a clean room. Moreover being ironic, the mother expresses a negative attitude about the failure of this expectancy to find a clean room. 
(1) A mother asked her son to clean up his messy room, but he was lost in a comic book. After a while, she discovered that his room was still messy, and said to her son: This room is totally clean!

The negative attitude concerning failed expectancy can be indirectly expressed thanks to several verbal (e.g., prosody, lexical markers) and non verbal cues (e.g., facial expression, gesture) (Utsumi, 2000) suggesting that prosody may contribute to understanding irony.

The impact on irony processing of different degrees of incongruity, between context and speaker's utterance, has been investigated with written material, showing that a larger contrast between expectations and reality (i.e., a high level of incongruity) increases the recognition of sarcasm (Gerrig and Goldvarg, 2000; Colston and O'Brien, 2000; Colston, 2002; Ivanko and Pexman, 2003) while the absence of incongruity between expectation and reality leads to interpreting the target utterance as sincere. In others words, the more incongruent the context is with the speaker utterance, the better sarcasm is perceived. For instance, if the mother says "This room is totally clean!" in the context of a messy room (reality) the high level of incongruity between the context and the expectation (finding a clean room) leads to an interpretation of the target utterance as sarcastic. Such a context would contrast more sharply with the expectations than if the mother uttered the same sentence when the room is clean but with some books on the floor, leading in this case to a less clear interpretation.

However, though these studies show that contextual incongruity plays a critical role in irony perception, they were conducted with written material. Generally, the participants' task consisted in reading a short story ending by a target utterance and judging whether this utterance was ironic or literal. Other studies have used auditory material to highlight the importance of prosody as a cue enabling the listener to detect irony. However, there has been no consensus regarding its role in understanding irony. Several researchers (Bryant and Fox Tree, 2002, 2005, Cheang and Pell, 2008, 2009; Rockwell, 2000; Voyer and Techentin, 2010; Loevenbruck et al., 2013) have shown that listeners are able to identify ironic and sarcastic utterances by relying on prosody without any contextual information, leading to the idea that an ironic intonation characterized by specific acoustic features may exist. Nevertheless, Rockwell (2000) found that, by comparison to spontaneous sarcasm (i.e., sarcasm spontaneously produced after the reading of a biasing sentence) only posed sarcasm (i.e., where it is asked to produce the utterance in a sarcastic way) can be discriminated from nonsarcasm by listeners. Bryant and Fox Tree (2005) also pointed out that only filtered utterances 
conveying dripping sarcasm (i.e., utterances in which sarcasm is conveyed in a semantically and prosodically unambiguous way) is perceived as more sarcastic than non-sarcastic utterances, compared to dry sarcasm (i.e., ambiguous utterance when presented only in written modality but which is clearly recognizable when presented auditorily). Research trying to specify which prosodic cues may be critical for marking sarcasm or irony has lead to mixed results depending on the different subtypes of irony investigated, the different methods used to elicit irony and the different languages studied. While other cues could be involved in different languages, modulations of mean F0, slower speech rate and longer syllable duration have been consistently shown to be acoustic features used to mark sarcasm or irony in English, French, Italian, German and Cantonese (See Scharrer and Christmann, 2011 for a cross-language review; Rockwell, 2000; Anolli et al. 2002; Attardo et al., 2003; Bryant and Fox Tree, 2005; Laval and Bert-Erboul, 2005; Cheang and Pell, 2009; Loevenbruck et al., 2013). Mean F0 has been suggested to be the most important acoustic parameter for marking sarcasm (Cheang and Pell, 2011), but there is evidence that this cue is used differently across languages, research in French and English reporting an increase F0 variability (Attardo et al.,2003; Laval and Bert-Erboul, 2005; Loevenbruck et al., 2013) while a study in Cantonese showed a reduced F0 range (Cheang and Pell, 2009).

While the impact of contextual incongruity or prosody on understanding irony has led to a significant amount of research, the influence of the interplay between these markers on irony and sarcasm understanding have only recently been investigated in English (Woodland and Voyer, 2011; Voyer et al., 2014; Peters et al., 2015) and in French (Deliens et al., 2017; Deliens et al., 2018). Developing different experiments in English, Voyer et al. (2014) found a strong interaction between context and prosody, concluding that prosody contributes to emphasizing the contrast effect in sarcasm perception. They manipulated the level of incongruity between the context and the speaker's utterance using three types of context (i.e., a positive context with no contextual incongruity leading to sincerity, a negative context with a strong contextual incongruity leading to sarcasm, an ambiguous context with a weak contextual incongruity) (Voyer et al., 2014). Their results revealed that the proportion of sarcastic responses in ambiguous contexts remained within the proportions obtained for congruent context-prosody pairs (e.g., negative context matched with sarcastic prosody and positive context matched with sincere prosody) and the incongruent pairs in the direction predicted by the prosody. In a study comparing the ability of native and non-native English speakers to use context and prosody in sarcasm understanding, Peters et al. (2015) asked 
participants to answer a comprehension question (e.g., "Did Angie think John did a good job?"). Answers were based on participants' interpretation of a character's intention as sarcastic or sincere. They showed that non-native English speakers always relied on context, ignoring prosody for the understanding of sarcasm, whereas native English speakers relied on both context and prosody but paid more attention to context than prosody when prosody was incongruent with context. In French, Deliens and colleagues (Deliens et al., 2017; Deliens et al., 2018) found different results depending on the nature of the task (discrimination task versus interpretation task). They showed that context is a highly reliable cue to understand sarcasm but its processing is time consuming. They suggested that participants by-passed contextual cues and used prosodic cues to make an accurate discrimination between sarcastic and literal meaning with the least processing effort (Deliens et al., 2017). When involved in an interpretation task (i.e., an act-out comprehension task inspired by Kowatch et al., 2013) participants used the same strategy (Deliens et al., 2018). However, with this kind of task, they were faster but less accurate when prosodic cues were added, prosody being a less reliable cue than context incongruity. In this study, participants were asked to watch videos of two people having short conversations. Following a situational context, participants had to listen to what the first person says (i.e., a question about two items on a table: Would you like the physics book as a gift?) and to the second person's answer (i.e., target utterance: Yes, you know how much I like physics). Then they had to give the second person the item they believe he/she really wanted by clicking the mouse button.

The absence of consensus amongst these studies could be explained by the use of different kinds of task (e.g., rating of prosodic cues in Woodland and Voyer (2011), discrimination task in Voyer et al. (2014) and Deliens et al. (2017), interpretation task in Deliens et al. (2018) and Peters et al., (2015) with the presence or not of time limit to answer in these studies) and by the presence of individual differences regarding how people use prosody when understanding utterances. Bishop and colleagues (Bishop, 2012; Jun and Bishop, 2015) suggested that the use of prosodic information for sentence interpretation may differ across English-speaking listeners. While typical subjects are able to integrate contextual information and prosody to understand sarcasm, it has been suggested that individual differences (e.g., in terms of cognitive resource capacity (Peters et al., 2015), in terms of fatigue level (Deliens et al., 2015)) could lead to different strategies when relying on these markers to detect irony. However, none of the studies reported above investigated such individual differences in the comprehension of irony. 
To our knowledge, except the studies by Deliens and colleagues $(2017,2018)$ there have been no studies in French among adults assessing the effect of both context and prosody on irony understanding. Unlike Deliens et al. (2017, 2018), in the present study, we manipulated the degree of incongruity between context and speaker utterance as Voyer et al. (2014) did for English. We used this paradigm because we supposed that if participants relied on prosody to understand ironic sentences it would be more apparent with the stimuli presented in a weak incongruity context condition (i.e., the ambiguous condition) than with those presented in the other conditions.

Thus, the aim of the present study was to determine - in French - the relative influence of both contextual incongruity and prosody on understanding irony, and to explore whether individual differences regarding the relative influence of these markers of irony exist. More precisely, we explored whether all participants relied on both prosody and contextual incongruity to understand irony or whether some participants relied more on contextual incongruity than on prosody to understand irony. We hypothesized that the combination strong incongruity context condition/ironic prosody would be judged as ironic whereas the combination no incongruity context condition/neutral prosody would be judged as non ironic. We also expected that if prosody facilitates ironic interpretation, stimuli presented with an ironic prosody would be judged as more ironic than those presented with a neutral prosody and that such a pattern would be particularly clear for stimuli in the weak incongruity context condition. Given that individual differences have been found regarding sensitivity to prosody and that contextual incongruity seems to be a more powerful marker of irony than prosody we supposed that some participants in our sample would rely more on contextual incongruity than on prosody to judge the speaker utterance.

\section{Method}

\subsection{Participants}

Ninety-five participants (30 males, 65 females) between 18 and 59 years old (mean age: 21.60, SD: 6.30; mean education: 12.61, SD: 1.30) were included in this study. They were all native French speakers, right-handed, and reported normal hearing at the time of the experiment. Written consent forms were obtained from all participants.

\subsection{Materials}

The stimuli were composed of 20 stories by Champagne-Lavau et al. (2012) adapted in French from Ivanko \& Pexman (2003) and controlled for familiarity and plausibility. Each 
story comprised a situational context followed by a target sentence (e.g., Christine is a clever student). The contexts were manipulated according to the strength of context incongruity (strong incongruity, weak incongruity, no incongruity) between contextual information and target sentence (cf. table 1). Each story was presented in each of the three context conditions intended to trigger either the literal meaning (no incongruity) or the ironic meaning (strong incongruity, weak incongruity) of the target sentence. Each target sentence was pronounced either with an ironic prosody or with a neutral prosody, while the contexts were all pronounced with a neutral prosody. Thus, there were six versions of each stimulus (20 stories x 3 context conditions x 2 prosody $=120$ stimuli), which were divided into 6 groups of 20 stimuli, according to a Latin square design, so that each participant heard each story once, in one of the six experimental conditions.

Table 1: Sample stimuli in the three context conditions and two prosody conditions

\begin{tabular}{|c|c|c|c|}
\hline & \multicolumn{3}{|c|}{ Type of context incongruity } \\
\hline & No incongruity & Weak incongruity & Strong incongruity \\
\hline Context & $\begin{array}{l}\text { Christine and Marie } \\
\text { sat the same math } \\
\text { exam. Christine } \\
\text { studied for } 1 \text { day and } \\
\text { got } 90 \% \text { in the exam. } \\
\text { The next day Marie } \\
\text { said to Chantal: }\end{array}$ & $\begin{array}{l}\text { Christine and Marie } \\
\text { sat the same math } \\
\text { exam. Christine } \\
\text { studied for } 2 \text { days } \\
\text { and got } 60 \% \text { in the } \\
\text { exam. The next day } \\
\text { Marie said to } \\
\text { Chantal: }\end{array}$ & $\begin{array}{l}\text { Christine and Marie } \\
\text { sat the same math } \\
\text { exam. Christine } \\
\text { hardly studied and } \\
\text { got } 20 \% \text { in the exam. } \\
\text { The next day Marie } \\
\text { said to Chantal: }\end{array}$ \\
\hline Ironic prosody & $\begin{array}{l}\text { Christine is a clever } \\
\text { student }\end{array}$ & $\begin{array}{l}\text { Christine is a clever } \\
\text { student }\end{array}$ & $\begin{array}{l}\text { Christine is a clever } \\
\text { student }\end{array}$ \\
\hline Neutral prosody & $\begin{array}{l}\text { Christine is a clever } \\
\text { student }\end{array}$ & $\begin{array}{l}\text { Christine is a clever } \\
\text { student }\end{array}$ & $\begin{array}{l}\text { Christine is a clever } \\
\text { student }\end{array}$ \\
\hline
\end{tabular}

All the stimuli were recorded by a male actor who was a native speaker of French. They were recorded using a digital recorder in a soundproof room. In the first session, the actor was asked to produce each target sentence with the appropriate prosody (i.e., ironic, neutral) after reading a situational context leading to either an ironic interpretation or a non-ironic interpretation of the target utterance. In the second session, he was asked to produce contexts with a neutral intonation. Thus, contexts were recorded once while target sentences were recorded twice (with an ironic prosody and with a neutral prosody). A perception study was then performed to ensure that target utterances were perceived as correctly reflecting the intended prosody (ironic prosody, neutral prosody). Fifteen undergraduate students from AixMarseille University, not involved in the main experiment, were asked to rate on a 5-point 
Likert scale $(1=$ not ironic, $5=$ very ironic $)$ to what extent each target sentence was ironic. The 20 target sentences were presented orally without context through headphones. The 20 target sentences presented with an ironic prosody $(\mathrm{M}=3.61, \mathrm{SD}=0.35)$ were judged as significantly more ironic than their counterpart presented with a neutral prosody $(M=1.07$, $\mathrm{SD}=0.08)(\mathrm{t}(19)=-31.18, \mathrm{p}<0.0001)$. The following acoustic parameters were measured for each validated ironic and neutral utterances using Praat speech analysis software (Boersma and Weenink, 2015): mean fundamental frequency (f0) in $\mathrm{Hz}$, pitch span (computed by subtracting the minimum from the maximum $f O$ value (in semitones) for each utterance as a further index of pitch variation) in $\mathrm{Hz}$ and duration (in s).

Unpaired $\mathrm{t}$ test comparing ironic and neutral prosody conditions revealed that target utterances with ironic prosody had a higher mean fundamental frequency (mean $=132.8$, SD $=12.3 ; \mathrm{t}(38)=-2.268, \mathrm{p}<0.03)$ and a longer duration $($ mean $=2.1, \mathrm{SD}=0.41 ; \mathrm{t}(38)=-2.907$, $\mathrm{p}<0.01$ ) than target utterances with neutral prosody (respectively, mean $\mathrm{f} 0=124.5, \mathrm{SD}=$ 10.7; mean duration $=1.7, \mathrm{SD}=0.4)$. These results were consistent with those of Loevenbruck et al. (2013) in French.

\subsection{Procedure}

Participants were tested in group of at most 10, in a quiet room. They were seated comfortably in front of a computer screen. Stimuli were presented using headphones. The volume was left to the discretion of each participant. Participants were instructed to listen to each story, and to judge as quickly as possible if the final target utterance was ironic or not, taking into account all the information. Before running the experiment, participants began with a short practice block of 3 trials. They listened to the situational context. After a $400 \mathrm{~ms}$ interval, they listened to the target utterance. At the end of the target utterance, a red cross appeared at the center of the screen, indicating participants that they had to respond by pressing the key corresponding to their answer (i.e., ironic, non-ironic) on the keyboard. Labels "I" for ironic and "NI" for non-ironic were stuck on the respectively " 1 " and "3" key of the keyboard. Half of the answers were "ironic" while the other half was "non-ironic". The next trial started immediately after the participant's response. The experiment was divided into two blocks of ten trials, in order to give participants a break in the middle of the task. Stimuli were presented in random order for all participants. The presentation of the experiment was programmed using E-Prime 2.0 software (Psychology Software Tools, Pittsburgh, PA). Responses and response times were also recorded with this software. 


\section{Data analyses}

To explore whether some participants in the group relied more on contextual incongruity than on prosody to understand irony, we performed a hierarchical cluster analysis based on the percentage of ironic responses for the weak incongruity context condition (with both neutral and ironic prosody) using the Ward's method (Ward, 1963). We used percentage of ironic response in this context condition to perform the cluster analysis since we thought that the impact of prosody would be strongest on this condition. This method (For details see Ward, 1963; Everitt, 2011) allowed us to classify our sample of participants into a number of different subgroups such that similar participants were grouped in the same subgroup. More precisely, the Ward's method is an agglomerative method which combines clusters whose grouping leads to the minimum increase in total within-cluster variance. This method is preferred because it minimizes the increase in total within-cluster sum of squared error. This increase is proportional to the squared Euclidean distance between cluster centers. This hierarchical cluster analysis revealed two clusters suggesting two patterns of performance. Subsequent analyses of variance on the ironic percentage of responses and the response times (ANOVAs) allowed us to specify these patterns of performance according to the use of prosody and context. We chose to name these two subgroups "PROSODY-" and "PROSODY+" according to the results of the analyses of variance. To simplify the presentation of the results we used these names to describe the two clusters obtained in the hierarchical cluster analysis. The PROSODYsubgroup contained 55 participants while the PROSODY+ subgroup involved 40 participants. The two subgroups differed neither in age $(\mathrm{t}(93)=0.074 ; \mathrm{p}>0.05)$ nor years of education $(\mathrm{t}(93)=-1.544 ; \mathrm{p}>0.05)$. A 3-Context (strong incongruity, weak incongruity, no incongruity) x 2 Prosody (ironic, neutral) x Group (PROSODY+, PROSODY-) repeated-measures ANOVA was performed on the percentage of ironic responses and on response times (RT). The alpha level was set at $\mathrm{p}<0.05$ for all the analyses. Statistical analyses were performed with SPSS 22.0 (IBM Corp., 2012).

\section{Results}

\subsection{Proportion of ironic responses analyses}

The Context x Prosody x Group ANOVA showed a significant main effect of group $(\mathrm{F}(1,93)$ $\left.=43.025, \mathrm{p}<0.0001, \mathrm{n}_{\mathrm{p}}{ }^{2}=0.316\right)$, meaning that the PROSODY-group judged utterances as more ironic than the PROSODY+ subgroup whatever the context and prosody conditions (cf. Figure 1). A main effect of Context $\left(F(2,186)=357.167, p<0.0001, \eta_{p}{ }^{2}=0.793\right)$ and a main 
effect of Prosody $\left(F(1,93)=17.622, p<0.0001, \eta_{p}{ }^{2}=0.159\right)$ were also found, meaning that participants perceived the stimuli with an ironic prosody as more ironic than the stimuli with a neutral prosody whatever the context condition. Pairwise comparisons revealed that all the context conditions were different from one other $(\mathrm{p}<0.0001)$, following the pattern: strong incongruity $>$ weak incongruity $>$ no incongruity. The interactions Context $x$ Group $(F(2,186)=$ 16.359, $\left.\mathrm{p}<0.0001, \mathrm{n}_{\mathrm{p}}{ }^{2}=0.150\right)$, Prosody x Group $\left(\mathrm{F}(1,93)=22.907, \mathrm{p}<0.0001, \mathrm{n}_{\mathrm{p}}{ }^{2}=0.198\right)$ and Context $x$ Prosody $\left(F(2,186)=4.351, \mathrm{p}<0.014, \eta_{\mathrm{p}}{ }^{2}=0.045\right)$ were significant. Decomposition of the Context $x$ Group interaction revealed that in the weak incongruity context condition participants from the PROSODY- subgroup judged stimuli more ironic than participants from the PROSODY+ subgroup $(\mathrm{p}<0.0001)$ while no difference was found for the no incongruity context and the strong incongruity context conditions $(p>0.05)$. See figure 2. Decomposition of the Prosody $x$ Group interaction showed that participants from the PROSODY+ subgroup judged stimuli with an ironic prosody to be more ironic than stimuli with a neutral prosody $(\mathrm{p}<0.0001)$ whatever the context condition while such a difference was not found for the PROSODY- subgroup ( $\mathrm{p}>0.05$ ). Decomposition of the Context $\mathrm{x}$ Prosody interaction according to the incongruity context condition showed that participants judged the stimuli presented with an ironic prosody to be more ironic than those presented with a neutral prosody for the no incongruity context condition $(\mathrm{p}<0.03)$ and for the weak incongruity context condition ( $\mathrm{p}<0.0001)$ while such a difference did not exist for the strong incongruity context condition ( $\mathrm{p}>0.05$ ). The Context $\mathrm{x}$ Prosody $\mathrm{x}$ Group interaction was also significant $\left(F(2,186)=23.872, p<0.0001, n_{p}{ }^{2}=0.204\right)$. Decomposition of this interaction according to group revealed that in PROSODY+ subgroup, participants judged stimuli with an ironic prosody to be more ironic than stimuli with a neutral prosody for both the weak $(\mathrm{p}<$ $0.0001)$ and the no incongruity context condition ( $<<0.001)$. In the PROSODY- subgroup such a difference was only found for the weak incongruity context condition $(\mathrm{p}<0.024)$ but the other way around (ironic prosody < neutral prosody). 
Figure 1. Percentage of ironic responses by context conditions and prosody conditions

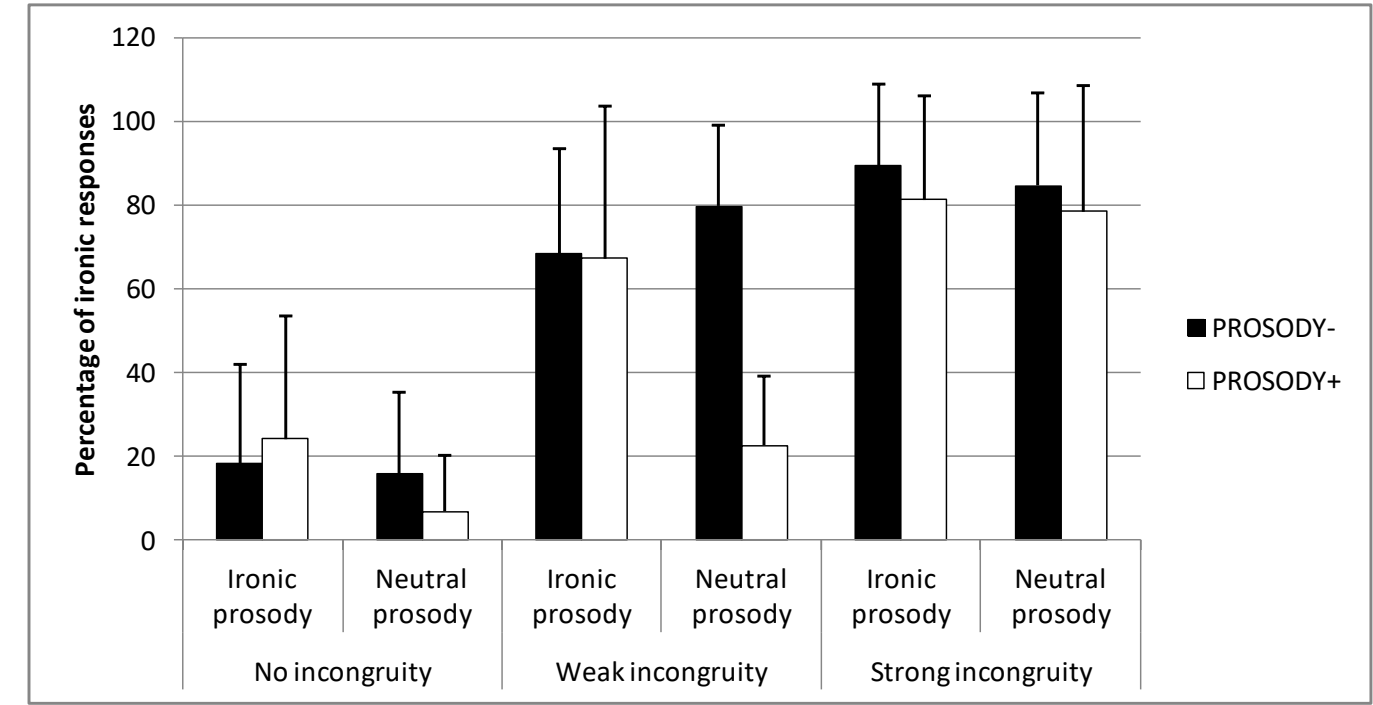

Bars represent standard deviations

Figure 2. Percentage of ironic responses by context conditions

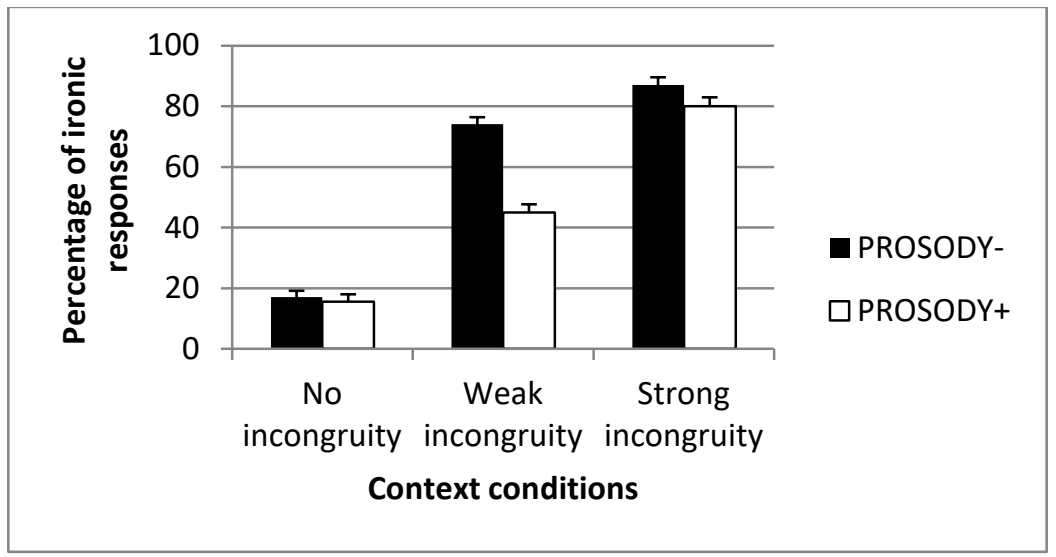

Bars represents standard errors

\subsection{RT analyses}

The Context x Prosody x Group on the RT showed a significant Group effect $(\mathrm{F}(1,93)=$ 3.969, $\left.\mathrm{p}=0.049, \eta_{\mathrm{p}}{ }^{2}=0.041\right)$ meaning that participants from the PROSODY-subgroup were faster than participants from the PROSODY+ subgroup in judging the stimuli as ironic or not. There was a main effect of Context $\left(\mathrm{F}(2,186)=4.493, \mathrm{p}<0.012, \eta_{\mathrm{p}}{ }^{2}=0.046\right)$. Pairwise comparisons revealed a higher RT for weak incongruity context condition than for strong incongruity condition $(\mathrm{p}<0.011)$. There was no main effect of Prosody $(F(1,93)=2.131, p>$ $\left.0.05, \eta_{p}{ }^{2}=0.022\right)$. The interactions Context x Group $\left(F(2,186)=1.520, p>0.05, \eta_{p}{ }^{2}=0.016\right)$, Prosody x Group $\left(\mathrm{F}(1,93)=0.080, \mathrm{p}>0.05, \eta_{\mathrm{p}}{ }^{2}=0.001\right)$ and Context $\mathrm{x}$ Prosody $(\mathrm{F}(2,186)=$ 
3.455; $\left.p>0.05, \eta_{p}^{2}=0.036\right)$ and Context $x$ Prosody x Group $\left(F(2,186)=0.074, p>0.05, \eta_{p}^{2}\right.$ $=0.001)$ were not significant (cf. Figure 3).

Figure 3. Response time by context conditions and prosody conditions.

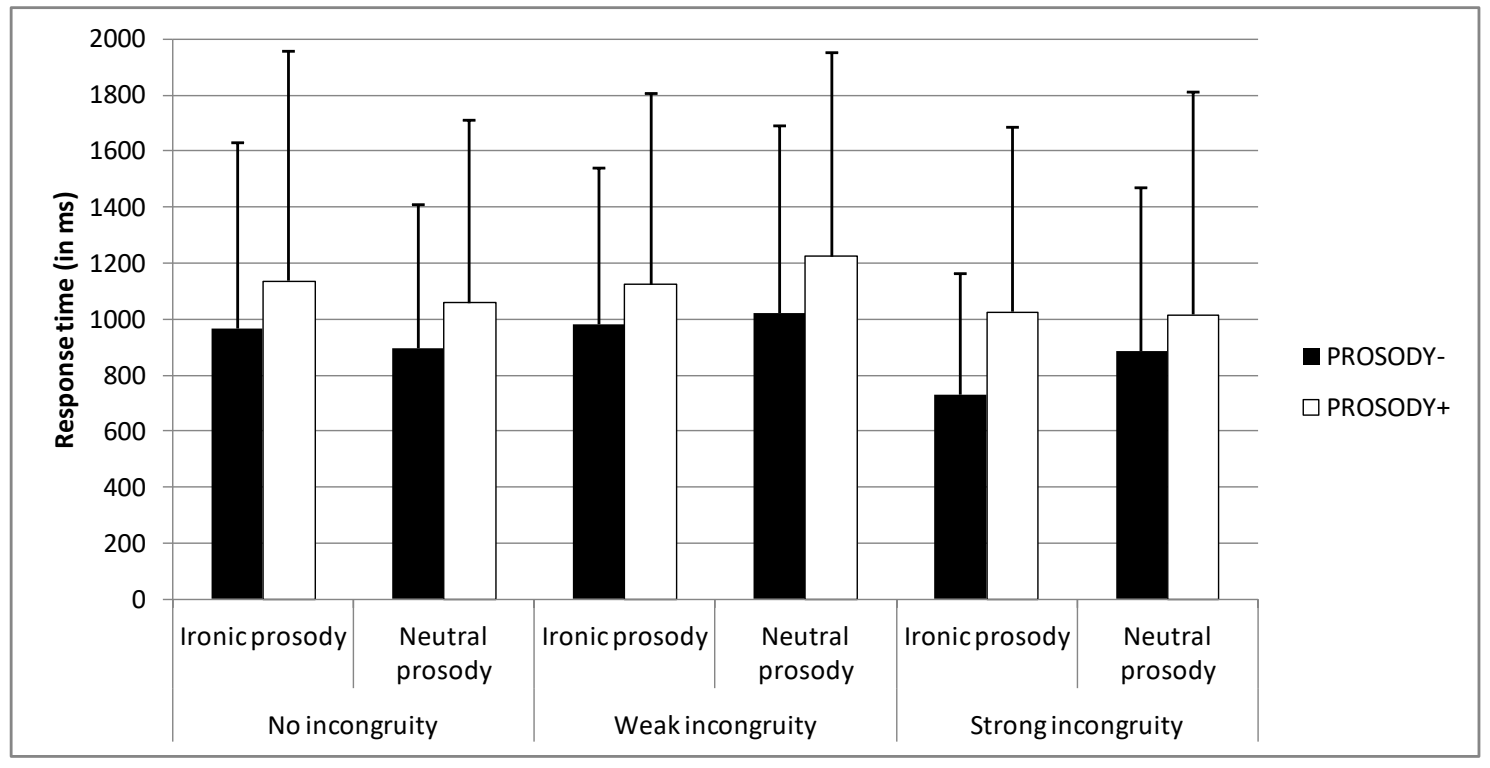

Bars represent standard deviations

To sum up, these results showed that, in contrast to participants from the PROSODYsubgroup, participants from the PROSODY+ subgroup judged speaker's utterances to be more ironic when uttered with an ironic prosody than when they were uttered with a neutral prosody particularly in the weak incongruity and no incongruity context conditions. Thus, the PROSODY- subgroup contained participants who relied more on context than on prosody while the PROSODY+ subgroup involved participants who relied more on prosody than on context to interpret the speaker utterance as ironic. For both these subgroups stimuli presented in the weak incongruity context condition took longer to judge than those presented in the strong incongruity context condition.

\section{Discussion}

The aim of this research was to investigate the relative influence of both contextual incongruity and prosodic cues on irony comprehension and to explore whether all participants relied on both prosody and contextual incongruity to understand irony or whether some participants relied more on contextual incongruity than on prosody to understand irony. To this aim, we used an irony-discrimination task in which participants had to decide whether the speaker of the target utterances was being ironic or not. The level of contextual incongruity 
(strong incongruity, weak incongruity, no incongruity) and the prosody (ironic, neutral) were manipulated in the presentation of the stimuli.

The main results revealed the existence of two subgroups of participants who used prosody either more, or less, to decide whether the speaker was being ironic or not. We found that both the degree of contextual incongruity and prosody may impact the extent to which irony is understood. Our results pointed out the general impact of prosody in the subgroup named PROSODY+ compared to the subgroup named PROSODY-, meaning that the PROSODY+ subgroup judged the statements to be more ironic when uttered with an ironic prosody compared to statements spoken with a neutral prosody, specifically in the weak incongruity and no incongruity context conditions whereas this was not the case for the PROSODYsubgroup. The results obtained in the PROSODY+ subgroup were consistent with those in the second experiment of Voyer et al. (2014). Thus, we confirm that ironic prosody can be a reliable cue for irony understanding (Cheang and Pell, 2008; Voyer et al., 2014; Peters et al., 2015). However, while only one subgroup of participants in our study used prosody as a cue to understanding irony, all the participants relied on contextual incongruity when judging the speaker utterance as ironic or not. This confirms the findings of several authors concluding that context is a more powerful cue than prosody in irony understanding (Bryant and Fox Tree, 2002; Peters et al., 2015; Deliens et al., 2018). Our results also concur with previous findings showing that the greater the incongruity between context and speaker's utterance, the easier it is to perceive irony (Ivanko and Pexman, 2003, Voyer et al., 2014). In line with this impact of the degree of incongruity on irony understanding, stimuli in the weak incongruity context condition provoked slower responses than stimuli presented in the strong incongruity condition. It pointed out that participants had more difficulty deciding whether the speaker's utterance was ironic or not when the preceding context was weak (leading to ambiguity) than when it was strongly negative (Colston and O'Brien, 2000; Ivanko and Pexman, 2003; Champagne-Lavau et al., 2018).

While the studies combining prosody and contextual incongruity in tasks assessing irony and sarcasm understanding have confirmed the impact of contextual incongruity in both English and French (Woodland and Voyer, 2011; Voyer et al., 2014; Peters et al., 2015; Deliens et al., 2018), results regarding the impact of prosody in irony understanding were mixed. Depending on the subgroup found with the cluster analysis we observed different performances which could reconcile these mixed results. Indeed, our PROSODY+ subgroup relied on both contextual incongruity and prosody as showed by Voyer and colleagues (Woodland and Voyer, 2011; Voyer et al., 2014) and by Peters et al. (2015). By contrast, 
results from our PROSODY-subgroup were comparable to recent findings from Deliens et al. (2018) in French showing that participants relied less on prosody (in terms of accuracy) than on contextual incongruity to understand irony. However, Deliens et al. (2018) found that prosodic cues prompt a faster processing.

Participants from the two subgroups seemed to use different strategies to judge whether the speaker's utterance was ironic or not. RT results could suggest that participants from the PROSODY- subgroup have consciously decided to disregard the prosody, leading them to perform faster than participants from the PROSODY+ subgroup. Following this hypothesis, we should expect no difference between stimuli with an ironic prosody and those with a neutral prosody in all incongruity context conditions and also no main effect of prosody in terms of percentage of ironic responses. However, our results challenge this hypothesis since we found that participants from the PROSODY- subgroup judged stimuli with an ironic prosody to be less ironic than stimuli with a neutral prosody for the weak incongruity context condition. Thus, they seemed to be sensitive to prosody but they did not use it to interpret target utterances as ironic. It could be also more resource demanding to use both contextual incongruity and prosody, and thus to integrate contextual information and prosody than to rely only on contextual incongruity to interpret ironic utterances, especially as the stimuli were only presented auditorily. This could explain why PROSODY+ subgroup who relied on both context and prosody were slower than PROSODY- subgroup whatever the context incongruity and the prosody conditions. Indeed, participants would have to spread their attentional resources between different kinds of information to manage them (here context and prosody) to understand irony. Such a cognitive load could have led participants from the PROSODY- subgroup to not rely on prosody during the task. Our results are also in line with those of Bishop and colleagues (Bishop, 2012; Jun and Bishop, 2015) showing that the use of prosodic information for sentence interpretation may differ between listeners. They pointed out that people with autistic traits associated with communication skills (measured by the Autism Spectrum Quotient, Baron-Cohen et al., 2001) had varying levels of sensitivity to prosodic prominence perception compared to people without such autistic traits (Bishop, 2012; Jun and Bishop, 2015). Interestingly, they suggested that autistic traits could be related to a limited processing of resources (in terms of lesser attention-switching abilities). Thus, the extent to which people rely on both contextual incongruity and prosody to perceive irony seems to be subject to variation. Further research is required to account for the individual differences in using both these ironic markers. Results of the present study also deserve further investigation to assess whether a different experimental paradigm involving time 
pressure, for example, would lead to different patterns of performance. As suggested by Deliens et al. (2017), under time pressure all participants could choice a costlier strategy relying on prosodic cues to judge stimuli as ironic or not.

In conclusion, this study in French supports the claim that both contextual incongruity between context and speaker utterance and prosody may influence irony understanding. In addition, we showed for the first time that, while all participants of our sample used contextual incongruity to decide whether the speaker's utterance was ironic or not, prosody facilitated irony understanding in only part of them. Thus, context seemed to be a more reliable cue than prosody for ironic judgments (Bryant and Fox Tree, 2002; Deliens et al., 2018). An individual differences approach with a general cognitive assessment of the participants could be included in future research to better account for the cognitive processes involved in understanding irony.

\section{References}

Anolli, L., Ciceri, R., \& Infantino, M. G. (2000). Irony as a game of implicitness: Acoustic profiles of ironic communication. Journal of Psycholinguistic Research, 29(3), 275-311.

Attardo, S., Eisterhold, J., Hay, J., \& Poggi, I. (2003). Multimodal markers of irony and sarcasm. Humor - International Journal of Humor Research, 16(2), 243-260.

Baron-Cohen, S., Wheelwright, S., Skinner, R., Martin, J., \& Clubley, E. (2001). The autism Spectrum Quotient (AQ): Evidence from Asperger syndrome/high-functioning autism, males and females, scientists and mathematicians. Journal of Autism and Developmental Disorders, 31(1), 5-17.

Bishop, J. (2012). Focus, prosody, and individual differences in "autistic" traits: Evidence from cross modal semantic priming. UCLA Working Papers in Phonetics, 111, 1-26.

Boersma, P., and Weenink, D. (2015). "Praat. Doing phonetics by computer" (Version 5.4.01, 2015), Computer program: www.praat.org.

Bryant, G. A., \& Fox Tree, J. E. (2002). Recognizing verbal irony in spontaneous speech. Metaphor and Symbol, 17(2), 99-117.

Bryant, G. A., \& Fox Tree, J. E. (2005). Is there an ironic tone of voice? Language and Speech, 48, 257-277

Champagne-Lavau, M., Charest, A., Anselmo, K., Rodriguez, J. P., \& Blouin, G. (2012). Theory of mind and context processing in schizophrenia: The role of cognitive flexibility. Psychiatry Research, 200(2-3), 184-192. doi: 10.1016/j.psychres.2012.06.011 
Champagne-Lavau, M., Cordonier, N., Bellmann, A., \& Fossard, M. (2018). Context processing during irony comprehension in right-frontal brain-damaged individuals. Clinical Linguistics and Phonetics, 1-18. doi: 10.1080/02699206.2018.1430851

Cheang, H. S., \& Pell, M. D. (2008). The sound of sarcasm. Speech Communication, 50, 366-381.

Cheang, H. S., \& Pell, M. D. (2009). Acoustic markers of sarcasm in Cantonese and English. The Journal of the Acoustical Society of America, 126(3), 1394. doi: 10.1121/1.3177275

Cheang, H. S., \& Pell, M. D. (2011). Recognizing sarcasm without language: A crosslinguistic study of English and Cantonese. Pragmatics \& Cognition, 19(2), 203-223. doi: 10.1075/pc.19.2.02che

Colston, H., L. (2002). Contrast and assimilation in verbal irony. Journal of Pragmatics, 34, 111-142.

Colston, H., L., \& O’Brien, J. (2000). Contrast and pragmatics in figurative language: Anything understatement can do, irony can do better. Journal of Pragmatics, 32, $1557-1583$

Deliens, G., Stercq, F., Mary, A., Slama, H., Cleeremans, A., Peigneux, P., Kissine, M., 2015. Impact of acute sleep deprivation on sarcasm detection. PLOS ONE 10, e0140527. doi.org/10.1371/journal.pone.0140527

Deliens, G., Antoniou, K., Clin, E., \& Kissine, M. (2017). Perspective-taking and frugal strategies: Evidence from sarcasm detection. Journal of Pragmatics, 119, 33-45. doi: 10.1016/j.pragma.2017.08.002

Deliens, G., Antoniou, K., Clin, E., Ostashchenko, E., \& Kissine, M. (2018). Context, facial expression and prosody in irony processing. Journal of Memory and Language, 99, 35-48. doi: 10.1016/j.jml.2017.10.001

Everitt, B.S., Landau, S., Leese, M., \& D. Stahl (2011). Cluster Analysis, Fifth edition, Wiley series in probability and statistics.

Gerrig, R. J., \& Goldvarg, Y. (2000). Additive effects in the perception of sarcasm: situational disparity and echoic mention. Methaphor and symbol, 15(4), 197-208.

Gibbs, R. W. (1986). On the psycholinguistics of sarcasm. Journal of Experimental Psychology-General, 115(1), 3-15.

Grice, H. P. (1975). Logic and Conversation. In P. C. J. L. Morgan (Ed.), Syntax and Semantics: Speech Acts (Vol. 3, pp. 41-58). Academic Press, New York.

Ivanko, S. L., \& Pexman, P. M. (2003). Context incongruity and irony processing. Discourse Processes, 35(3), 241-279. 
Jun, S. A., \& Bishop, J. (2015). Priming Implicit Prosody: Prosodic Boundaries and Individual Differences. Language and Speech, 58, 459-473. doi: $10.1177 / 0023830914563368$

Kowatch, K., Whalen, J. M., \& Pexman, P. M. (2013). Irony Comprehension in Action: A New Test of Processing for Verbal Irony. Discourse Processes, 50(5), 301-315. doi: $10.1080 / 0163853 \times .2013 .799934$

Kumon-Nakamura, S., Glucksberg, S., \& Brown, M. (1995). How about another piece of pie : the allusional pretense theory of discourse irony. Journal of experimental Psychology: General, 124(1), 3-21.

Laval, V., \& Bert-Erboul, A. (2005). French-speaking children's understanding of sarcasm: The role of intonation and context. Journal of Speech Language and Hearing Research, 48(3), 610-620. doi: 10.1044/1092-4388(2005/042)

Lee, C. J., \& Katz, A. N. (1998). The Differential Role of Ridicule in Sarcasm and Irony. Metaphor and Symbol, 13(1), 1-15.

Loevenbruck, H., Jannet, M. A. B., D’Imperio, M., Spini, M., \& Champagne-Lavau, M. (2013). Prosodic cues of sarcastic speech in French: slower, higher, wider. In 14th Annual Conference of the International Speech Communication Association (Interspeech 2013) (p. 3537-3541).

Peters, S., Wilson, K., Boiteau, T. W., Gelormini-Lezama, C., \& Almor, A. (2015). Do you hear it now? A native advantage for sarcasm processing. Bilingualism: Language and Cognition, 19(02), 400-414. doi: 10.1017/s1366728915000048

Rockwell, P. (2000). Lower, slower, louder: vocal cues of sarcasm. Journal of Psycholinguistic, 29(5), 483-495.

Scharrer, L., \& Christmann, U. (2011). Voice Modulations in German Ironic Speech. Language and Speech, 54, 435-465. doi: 10.1177/0023830911402608

Searle, J. R. (1979). Expression and Meaning. Cambridge University Press, Cambridge.

Utsumi, A. (2000). Verbal irony as implicit display of ironic environment: distinguishing ironic utterances from nonirony. Journal of Pragmatics, 32, 1777-1806.

Voyer, D., \& Techentin, C. (2010). Subjective auditory features of sarcasm. Metaphor and Symbol, 25, 227-242.

Voyer, D., Thibodeau, S.-H., \& Delong, B. J. (2014). Context, Contrast, and Tone of Voice in Auditory Sarcasm Perception. Journal of Psycholinguistic Research, 45(1), 29-53. doi: 10.1007/s10936-014-9323-5 
Ward, J. H., Jr. (1963), "Hierarchical Grouping to Optimize an Objective Function", Journal of the American Statistical Association, 58, 236-244.

Woodland, J., \& Voyer, D. (2011). Context and intonation in the perception of sarcasm. Metaphor and Symbol, 26, 227-239. 